Gazi University
Journal of Science
PART C: DESIGN AND TECHNOLOGY
http://dergipark.gov.tr/gujsc

\title{
Estimates of hydroelectric energy generation in Turkey with Jaya algorithm- optimized artificial neural networks
}

\author{
ErgunUZLU ${ }^{*}$ (D) \\ ${ }^{1}$ Karadeniz Technical University Faculty of Engineering, Department of Civil Engineering, Trabzon/Turkey
}

\section{Article Info \\ Research article \\ Received:05/04/2021 \\ Revision: $16 / 07 / 2021$ \\ Accepted:18/07/2021 \\ Keywords \\ Jaya Algorithm ABC Algorithm Hydropower Generation Neural Networks}

\begin{abstract}
The main purpose of this study was to establish an artificial neural network (ANN) model trained by a Jaya algorithm, and use the model to predict Turkey's future hydroelectric energy generation (HEG). Population, gross domestic product (GDP), installed capacity, energy consumption, gross electricity energy demand (GEED), and average yearly temperature (AYT) data were inputted as independent variables in the model. ANN-Jaya was compared with ANN models trained by the other two high performance optimization methods, namely backpropagation (BP) and artificial bee colony $(\mathrm{ABC})$ algorithms, to test its accuracy. The ANNJaya model converged to smaller error values than values obtained with the ANN-BP and ANN$\mathrm{ABC}$ models for both the training and test datasets. When the average relative error (RE) values calculated for the test set are taken into account, ANN-Jaya performs $19.3 \%$ better than ANN$\mathrm{ABC}$ and $31.2 \%$ better than ANN-BP. Therefore, Turkey's HEG projections were made out to the year 2030 using an ANN-Jaya model in a low and a high energy demand scenario. According to the developed projections, HEG values in Turkey in 2030 will be in the range of 104.81-124.66 TWh. The present results affirm that HEG can be modeled accurately with an ANN-Jaya technique and this method was shown to be advantageous for predicting future HEG.
\end{abstract}

\section{INTRODUCTION}

In $2020,80 \%$ of energy consumption in the world was being met by fossil fuel resources. According International Energy Agency studies, the global primary energy demand is expected to increase by $45 \%$ in the next 20 years [1]. As shown in Figure 1, depletion of fossil fuel reserves-including oil, natural gas, and coal reserves - is accelerating due to ever-increasing global energy demands and reliance on fossil fuel resources is not sustainable. The insufficiency of fossil fuel resources to meet growing energy consumption demands is making it necessary for countries to undertake energy security measures. Additionally, there is growing awareness of the environmental harms caused by the $\mathrm{CO}_{2}$ emissions produced by fossil fuel combustion. 

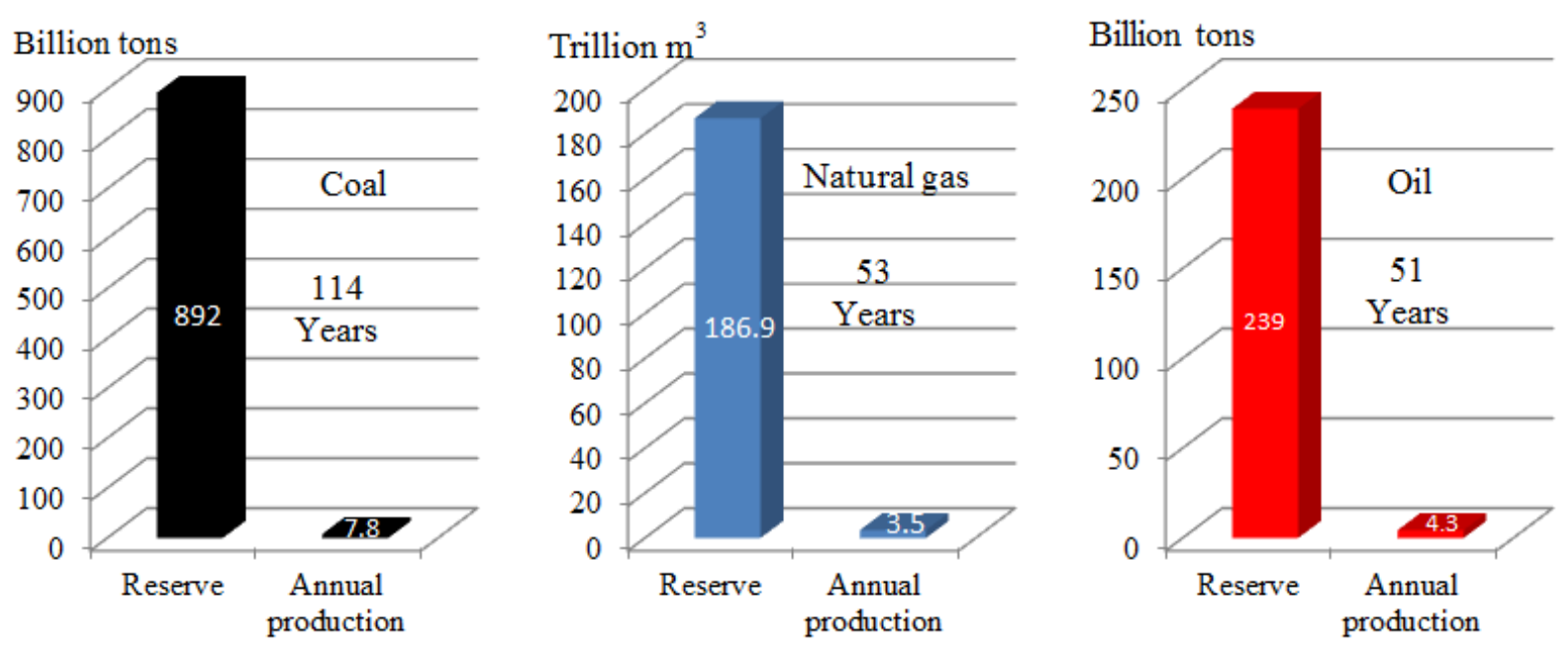

Figure 1.Remaining lifetimes of fossil fuel reserves [1].

The share of total domestic energy production from fossil fuels in Turkey is $57.5 \%$. (18,380MTOE ). This amount constitutes only $26.6 \%$ (31,944MTOE ) of Turkey's primary energy consumption [2]. Because Turkey does not have ample fossil fuel reserves, about half of its electricity consumption is delivered from imported sources (50.6\% in 2016) and, consequently, energy importation costs represent a heavy national economic burden. Indeed, energy imports account for $20 \%$ of the total imports into Turkey by cost. Dependence on imported energy sources represents one of the biggest challenges faced by developing countries, such as Turkey, in the $21^{\text {st }}$ century.

In 2018, the sources of energy used in Turkish electricity production were distributed as follows: coal, $37.2 \%$; natural gas, $30.3 \%$, hydropower $19.7 \%$, wind $6.5 \%$, solar $2.5 \%$, and geothermal energy $2.5 \%$ [3, 4]. Hydroelectric energy generation (HEG), which yielded 59.9 billion $\mathrm{kWh}$ in 2018 , is the biggest renewable contributor to electricity in Turkey. Increasing HEG is estimated to have the potential to produce 160 billion $\mathrm{kWh} /$ year in Turkey [3], which could play a vital role in developing sustainable domestic energy policies. While $24.7 \%$ of Turkey's electric energy consumption was supplied from hydroelectric energy in 2000, this rate declined to $19.7 \%$ in 2018 [4]. In recent years, there is a significant increase in amount of energy imported by Turkey. This increase jeopardizes the reliability of energy supply. Therefore, Turkish government has initiated a trend towards domestic resources in energy production. The private sector's interest in renewable energy sources increased with the "Electricity Market Law no. 4628" in 2001 and "Renewable Energy Incentive Law no. 5346" in 2005. In this way, the share of hydroelectric power plants in terms of installed power increased with new projects [5].

So far, 1244 hydroelectric power plants are in various stages of development in Turkey. 714 hydroelectric power plants have been put into operation, 37 are under construction and 493 are in various planning stages [6]. In 2018, the installed capacity and annual average energy generation capacity of the hydroelectric power plants in operation reached approximately 28,291 MW and 59.9 TWh, respectively [4]. According to these data, only $43 \%$ of Turkey's technically and economically hydroelectric potential has been developed. Thus, Turkish government should rapidly take hydroelectric power plants into operation in order to meet the increasing demand for electrical energy and to reduce the current account deficit.

Energy production and consumption projections are used to inform energy policy decisions.Unfortunately, official HEG estimates made by the Turkish Electricity Transmission Corporation (TEIAS) are considered to be unreliable and to be overestimated due to political concerns [7]. The Turkish government needs realistic HEG projections to undertake effective energy investment planning and meet future energy needs. Moreover, accurate short-term HEG predictions are needed to ensure adequate and uninterrupted electrical energy. Incorrect estimates can lead to disruptions in electrical energy supply or wasted energy. Obtaining precise estimates of HEG has been difficult because HEG is affected by a wide variety of factors, including climate, population, economic growth, and the status of energy facilities [7]. 
According to the literature review, there has no previously published study predicted HEG values of Turkey between the years of 2019-2030. In this study, a realistic HEG projection has been developed. The obtained projection is planned to be a guide to decision makers in Turkey's energy investments. Thanks to the obtained projection, the country's economic resources related to energy investments will be used more efficiently and the country will get rid of the heavy import burden on the economy. In addition, realistic energy investment plans can be made to increase renewable energy production. Furthermore, Turkey's climate change policies can be developed.

The aim of this study was to develop a predictive model for Turkey's future HEG and thus contribute to the development of policies aimed at increasing the domestic energy supply in Turkey. Towards this aim, a hybrid model consisting of artificial neural networks (ANNs) and a Jaya algorithm was developed to produce HEG predictions. The model is informed by six types of input data: GDP (gross domestic product), population, average yearly temperature (AYT), installed capacity, gross electricity energy demand (GEED), and energy consumption. This new ANN-Jaya model method was employed to obtain future HEG value estimates for two scenarios.

\section{LITERATURE REVIEW}

Energy estimation methods include primarily statistical methods and artificial intelligence methods. Regression analyses, autoregressive integrated moving average (ARIMA) models, and grey estimation models commonly use statistical methods. However, because statistical methods require precise mathematical expressions, they are not readily adaptable to the fluctuations in independent variables that affect HEG and thus not well suited for HEG estimation. This limitation can be overcome with the use of artificial intelligence methods that advance nonlinear modeling abilities and do not depend on precise mathematical expressions, including ANNs, fuzzy logic, genetic algorithm, artificial bee colony (ABC), teaching learning based optimization (TLBO), ant colony optimization, and particle swarm optimization algorithms.

Geem and Roper [8], Ekonomou [9], and Kankal et al. [10] used ANN and regression analysis techniques to estimate energy consumption in South Korea, Greece, and Turkey, respectively. In all three studies [8, 9, 10], ANNs gave better results than regression analyses. Similarly, Pao [11] and Kandananond [12] found that ANN methods were more effective than statistical methods, such as ARIMA, for estimating electrical energy consumption in Taiwan and Thailand, respectively. Hence, these aforementioned studies indicate that ANN methods are superior to statistical methods for energy modeling. On the other hand, Uzlu [13] and Uzlu and Dede [14] used ANN-Jaya technique to estimate Turkey's future energy consumption and electricity consumption values, respectively. They utilized GDP, population, import and export data as independent variables in their models. They found that ANN-Jaya give better results than ANN-ABC and ANN-TLBO. In this study, six independent variables were used different from other ANN-Jaya models $[13,14]$. This situation increased the number of ANN weights to be optimized and complicates the optimization problem. However, this problem can be solved by increasing the number of iterations and run numbers. ANN-Jaya algorithm gives better results than other algorithms for different data sets. This is a proof of its optimization power.

Similar statistical methods and ANNs have been used to make HEG projections. Wang et al. [15] used grey modeling and the seasonal autoregressive integrated moving average (SARIMA) methods to estimate HEG in China, and obtained better results with the former than the latter. To estimate Canada's hydroelectric energy potential, Coulibaly and Anctil [16] developed an ANN model and developed an ANN-training method called the optimal weight estimate procedure. In Turkey, Cinar et al. [17] trained ANNs with a genetic algorithm and a back propagation (BP) algorithm to predict HEG, and found that genetic algorithm-trained ANN models performed better than BP-trained ANN models. In their models, electrical energy consumption, primary energy consumption, installed capacity, population, and GDP are treated as independent variables. Using the ANN-genetic algorithm model, they obtained HEG predictions for the years of 2007 and 2012. Uzlu et al. [7] developed BP- and ABC-trained ANN models to obtain HEG projections for Turkey for the time period of 2012-2021, with the ABC algorithm yielding better ANN training results than the BP algorithm. GEED, population, energy consumption, and AYT were used as input data in the model. 
Although numerous studies related to energy consumption have been conducted, there have only been two studies that have modeled future HEG, both of which were mentioned above [7, 17]. Energy production projections are at least as important as energy consumption projections for national energy planning. Many studies have demonstrated the importance of Turkey's hydroelectric potential [18, 19, 20, 21, 22]. HEG projections are needed to inform investment planning for energy security as well as to guide the development of policies regarding alternative energy sources and climate change.

The Jaya technique proposed herein involves a new meta-heuristic algorithm, that is both simple and robust. The technique can be used to solve optimization problems that are either constrained or unconstrained. Although Jaya is relatively new, it has been applied in several engineering fields. Also, some researchers $[13,14]$ have used Jaya in energy modeling area to cope with the ANN problems of memorization and getting stuck in a local minimum. They found that the ANN-Jaya showed better performance than ANN-ABC and ANN-TLBO due to reasons such as the low number of control parameters in Jaya, the simpler structure of the algorithm and its convergence to the optimum solution requiring less effort. Furthermore, Jaya has better performance than other advanced optimization techniques including PSO and differential evaluation [23-25].

The facts that the Jaya algorithm has a high progression of fitness speed, it does not stick to local optima, does not search in abandoned areas, uses the random search feature more efficiently when faced with the problem of memorization, or when it cannot obtain a better result from the source, make Jaya superior to other algorithms. In addition, setting the optimum values for the control parameters of the metaheuristic algorithms is a very difficult task. While other metaheuristic algorithms include three or more control parameters, the Jaya algorithm has only two control parameters (maximum iterations and population size), making it advantageous compared to other meta-heuristic algorithms.

In this study, Turkey's future HEG potential is predicted with a hybrid ANN-Jaya algorithm model designed to output HEG projections. Economic, social, and climate factors that affect hydroelectric energy consumption, including GDP, population, AYT, installed capacity, GEED, and energy consumption, were used as input data in the models. Notable features that distinguish this study from others are listed below.

- A realistic and applicable HEG projection method was developed and applied to Turkey. There are no published HEG projections for Turkey for the years 2019-2030.

- The error values associated with the developed model are smaller than errors in other similar studies in the literature, and the model has high predictive power.

- The ANN-Jaya technique was used for the first time in a HEG prediction model.

- For the first time in HEG estimation, a model was created that incorporates GDP, population, AYT, installed capacity, GEED and energy consumption data.

This study has practical applications related to HEG and new energy sectors.

\section{METHODOLOGY}

\subsection{ANN Model}

ANN models with a single hidden layer have been demonstrated to perform successfully $[7,10,26]$. In addition, if a single hidden layer is used, the number of ANN weights to be optimized is reduced, making ANN training easier. Therefore, here, a multilayer feed forward neural network consisting of single input, output, and hidden layers was used to predict HEG. Because there is no exact method for determining the number of neurons to be included in the hidden layer, the number was determined by trial and error [27, 28]. In previous studies $[10,26]$, use of $5,10,15$, and 20 neurons in the hidden layer have yielded good results. Therefore, ANN architectures with 5, 10, 15, and 20 neurons in the hidden layer were tested in this study. Inter-layer transfer functions were determined based on previous studies [7, 10,26]: a tangent sigmoid function and a linear function were used as transfer functions between the input and hidden layers and between the hidden and output layers, respectively. The weights of the ANN model were optimized with BP, ABC, and Jaya algorithms. 
The mean square error (MSE), calculated according to equation (1), was used as the objective function in the ANN models [27]. During ANN training, BP, ABC, and Jaya algorithms were tried to find optimum ANN weights that yield the smallest MSE value.

$$
M S E=\frac{1}{n} \sum_{k=1}^{n}\left(y_{k}-o_{k}\right)^{2}
$$

where $o_{k}$ is the estimated value of ANN, $y_{k}$ is the actual value, and $n$ is the total number of data.

\subsection{BP Algorithm}

The BP algorithm has been used successfully in ANN training since 1986 [29]. However, the predictive power of BP-trained ANN models has been limited by memorization and local minimum traps. In addition, the selection of initial weights and special control parameters, such as learning and momentum rates, affects BP algorithm performance. Because optimal learning and momentum ratio selection is challenging and without a consensus method, the most suitable values can only be determined by trial and error. This situation prolongs optimization and makes ANN training difficult. The BP algorithm is quite mature and has been described in detail many times [7, 10, 26, 27, 29]. Thus, only a summary of its principles is provided here. First, the BP algorithm selects ANN weights randomly from within a predetermined range and calculates results using the selected weights. The proximity of the calculated value to an empirical value is measured by means of a predetermined error criterion. The calculated error value is distributed among the ANN weights according to learning rate. The ANN weights are updated continuously depending on their contribution to the error function. In this way, the BP algorithm approaches optimal weights that give values closest to the empirical target result. The cycle continues until the predetermined maximum number of iterations or error value is reached.

\subsection{ABC Algorithm}

$\mathrm{ABC}$ is a colony optimization algorithm based on the working and food searching processes of bees that was developed by Karaboga. It is a powerful optimization technique that is frequently used in ANN training in many different fields and gives successful results. The basic components of the ABC algorithm and its general operation are briefly summarized here. In the ABC algorithm, each solution corresponds to a food source, and bees try to find the locations of the most suitable food sources (highest amount of nectar) in a solution space. Conformance is the error value found for the chosen solution. As the error value of the solution gets smaller, its suitability increases. In this study, the $\mathrm{ABC}$ algorithm searched for the most suitable ANN weights in lieu of the most suitable food resources. The algorithm includes scout, onlooker, and employee bees. Initially, the bee population consists only of (equal numbers of) onlooker and employee bees. An employee bee is assigned for each "food source" (ANN weight in this study) [30].

Regarding the algorithm's working principles, in the first stage, food sources are determined randomly by the algorithm. Then employee bees go to the algorithm-determined food sources and each calculates the amount of nectar present, thereby determining the suitability of the randomly chosen solutions. Employee bees share the information they gather with onlooker bees. Onlooker bees start looking for new sources near the most suitable source, based on the information from the employee bees. At this point, the onlooker bees turn into employee bees. If a better source cannot be found near a food source within the predetermined limit value, the worker bee leaves that source. Each employee bee that leaves a food source assumes the role of a scout bee. Scout bees choose new food sources randomly. The main difference between scout bees and onlooker bees is that they use external clues to find new food sources. In this way, the algorithm avoids becoming stuck in a local minimum and encountering memorization problems. The aforementioned series of events constitutes one cycle. The best solution in each cycle is recorded by the algorithm. The cycle is repeated until a predetermined number of cycles or desired error values are reached [30]. 


\subsection{JAYA Algorithm}

All meta-heuristic optimization algorithms require the inclusion of population size and number of iterations as control parameters. In addition to these, some algorithms require additional specific control parameters. For example, GA requires crossover probability, mutation probability, and a selection operator. The $\mathrm{ABC}$ algorithm requires parameters to limit the number of bees of each type. The particle swarm optimization, harmony search, cuckoo search, imperialist competitive, and differential evolution algorithms also have specific parameters [31]. The performance of these algorithms is dependent upon the correct choice of control parameters. Therefore, optimization algorithms with few control parameters, such as TLBO and Jaya algorithms, are very attractive.

A recently proposed Jaya algorithm provides population-based optimization with only two control parameters [23]. The Jaya algorithm includes only a single phase (unlike TLBO) and has a simple numerical structure [31]. Thus, it is simple to implement and code. Furthermore, Jaya does not get stuck in local minima, unlike other metaheuristic algorithms. These features make the Jaya algorithm superior to TLBO and other metaheuristic algorithms.

A Jaya algorithm flowchart is provided in Figure 2. First, a random initial population of solutions is produced. The objective function of the problem is used to determine the best and worst solutions. The algorithm's success is continuously improved by approaching an optimal solution while avoiding failure by to moving further away from relatively poor solutions. In this way, all candidate solutions are updated.

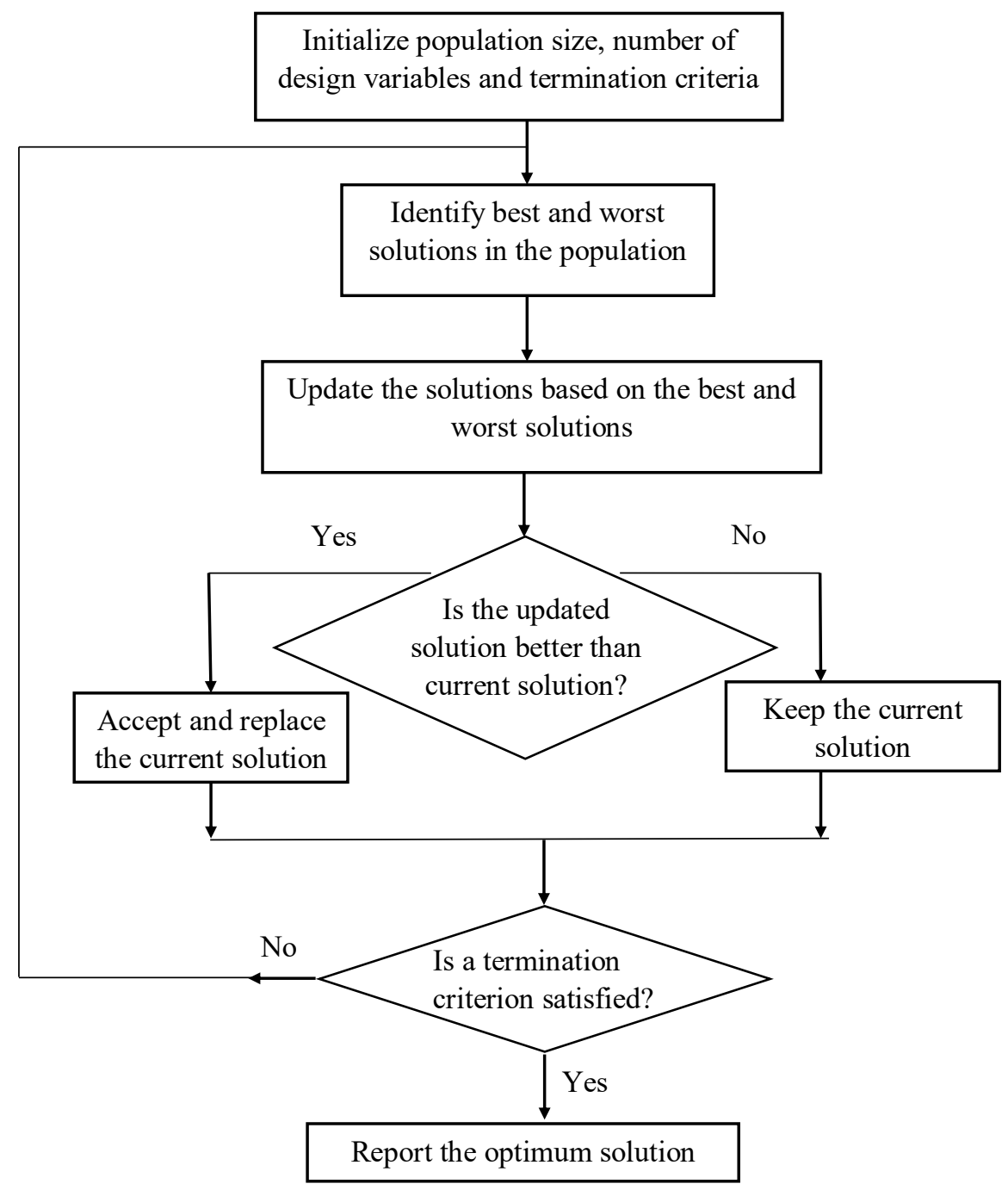

Figure 2. Flowchart of the Jaya algorithm [23, 32]. 
Jaya solutions are updated according to Eq. (2):

$$
X_{j, k, i}^{\prime}=X_{j, k, i}+r_{1, j, i}\left(X_{j, \text { best }, i}-\left|X_{j, k, i}\right|\right)-r_{2, j, i}\left(X_{j, \text { worst }, i}-\left|X_{j, k, i}\right|\right)
$$

where $X_{j, k, i}$ represents the value of the $j^{\text {th }}$ variable for the $k^{\text {th }}$ candidate in the $i^{\text {th }}$ iteration, $X_{j, b e s t, i}$ is the variable $j$ value of the best candidate, and $X_{j, \text { worst }, i}$ is the variable $j$ value of the worst candidate. $X_{j, k, i}^{\prime}$ is the updated value of $X_{j, k, i}$; and $r_{1, j, i}$ and $r_{2, j, i}$ are two random numbers in the range [0,1] generated for the $j^{\text {th }}$ variable during the $i^{\text {th }}$ iteration [32].

If the objective function of a newly proposed solution $\left(X_{j, k, i}^{\prime}\right)$ is less than that of the current solution $\left(X_{j, k, i}\right)$, then the new solution replaces the putative current solution. Otherwise, the algorithm preserves the current solution. This cycle is repeated until the convergence requirements have been met. Detailed information about the Jaya algorithm can be found in the literature [23, 31, 32].

\subsection{ANN Training}

Although the well-established BP algorithm gives very successful results in ANN training [7], its utility is limited by the risk of getting stuck in a best local solution, memorization problems, and difficulties with selecting control parameters [27]. Metaheuristic algorithms, such as ABC, TLBO, and JAYA, have been shown to give better results than BP in ANN training [7, 13, 26, 27]. In this study, to overcome the problems mentioned above and to develop an ANN model with high predictive power, herd-based optimization techniques, namely ABC and JAYA, were used in ANN training in addition to BP.

The weights and biases of ANN models were updated iteratively by a BP, ABC, or Jaya algorithm until the rates of change in the objective function decreased to an acceptable value (i.e., the objective function converges). The objective function to be minimized is in all cases was the MSE (1).

To evaluate how well the trained ANNs perform, average relative error (RE) [27], root mean square error (RMSE) values [7], mean absolute error (MAE) values [26], correlation coefficients (R values) [13], and U-statistic values [13] were determined. These measures describe the distance between the predicted energy consumption path $\left(y_{k}\right)$ and the true energy consumption path $\left(o_{k}\right)$. In eq. (7) below, $\bar{y}_{k}$ and $\bar{o}_{k}$ are means of predicted and real HEG values, respectively. RE, RMSE, MAE, U-statistic, and R values are defined as follows:

average $R E=\frac{\sum_{i=1}^{n}\left(\frac{y_{k}-o_{k}}{y_{k}}\right)}{n} \times 100$

$R M S E=\left[\frac{1}{n} \sum_{i=1}^{n}\left(y_{k}-o_{k}\right)^{2}\right]^{1 / 2}$

$M A E=\frac{1}{n} \sum_{i=1}^{n}\left|\left(y_{k}-o_{k}\right)\right|$

$$
U=\frac{R M S E}{\sqrt{\frac{1}{n} \sum_{i=1}^{n}\left(o_{k}\right)^{2}}+\sqrt{\frac{1}{n} \sum_{i=1}^{n}\left(y_{k}\right)^{2}}}
$$




$$
R=\frac{\left(\sum_{i=1}^{n}\left(o_{k}-\bar{o}_{k}\right)\left(y_{k}-\bar{y}_{k}\right)\right)}{\sqrt{\sum_{i=1}^{n}\left(o_{k}-\bar{o}_{k}\right)^{2} \sum_{i=}^{n}\left(y_{k}-\bar{y}_{k}\right)^{2}}}
$$

A maximum number of iterations of 5000 was selected for the BP, ABC and Jaya algorithms. Optimal learning and momentum ratios in the BP algorithm were determined by trial and error in the range of [0.1, 1]. Based on previous studies [7, 10, 17, 26, 27], initial weight values were selected in the range of [-0.01, 0.01] for the BP algorithm. A population size of 50 was selected for the $\mathrm{ABC}$ and Jaya algorithms. The limit value and quantity of employed/onlooker bees in the $\mathrm{ABC}$ algorithm were set to 100 and 25 , respectively. The weights of the ANN were initialized randomly in the range $[-1,1]$ in the ABC and Jaya algorithms. The MSE target value was set to $8 \times 10^{-8}$ for all three algorithms. The training process involves the application of a set of input vectors to the target network repeatedly, updating the weights in each subsequent iteration until a stop criterion (MSE or maximum iterations) is reached, as shown in the flowchart in Figure 3.

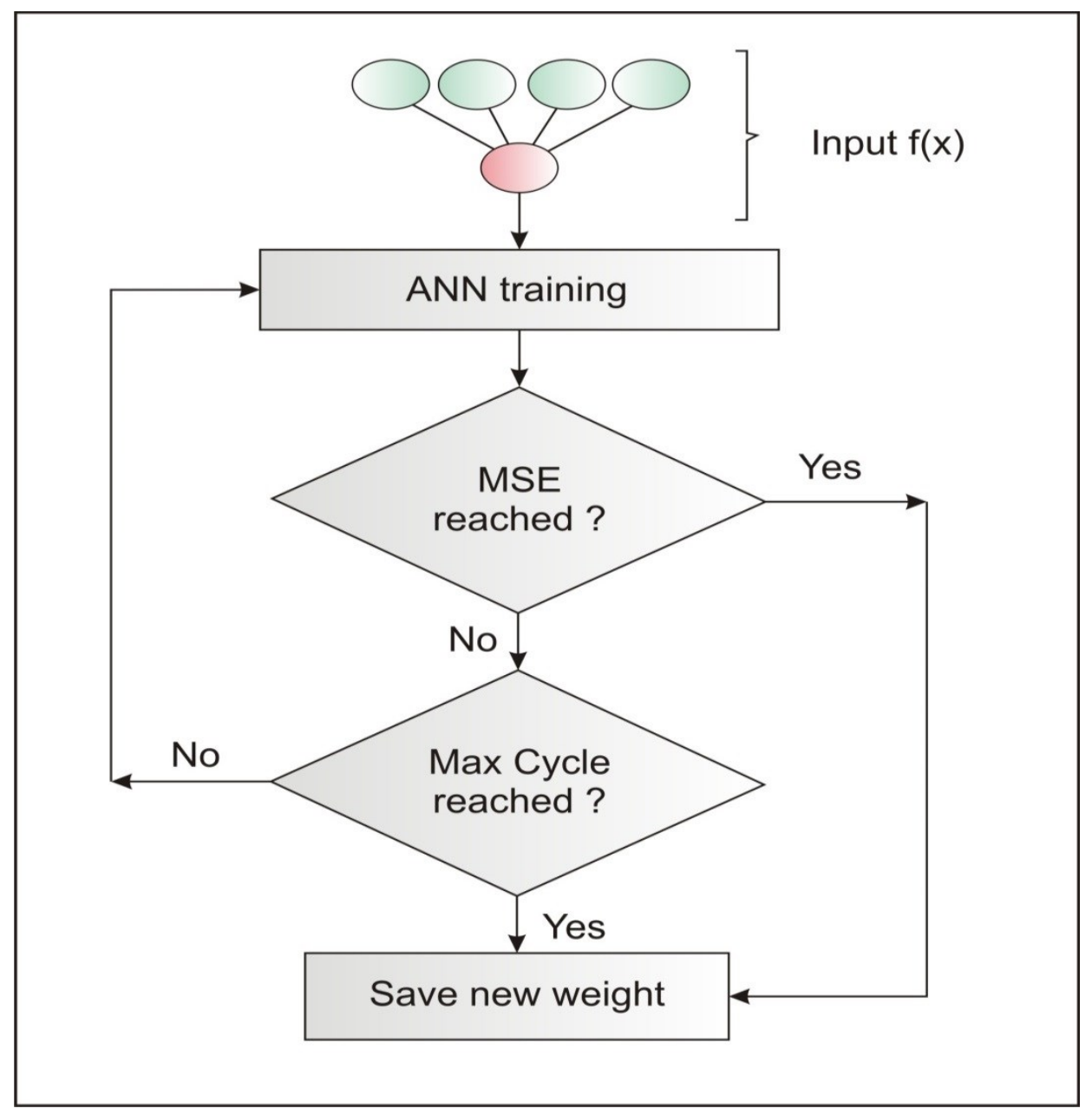

Figure 3. The proposed ANN training scheme [27]. 


\section{DETERMINATION OF INDEPENDENT VARIABLES AND DATA USED}

\subsection{Determining the Independent Variables}

HEG projections are difficult to produce due to HEG being affected by numerous parameters, including climate, demographic, and socio-economic factors. Population, GDP, installed capacity, energy consumption, GEED, and AYT have previously been determined to be the specific parameters that have the most pronounced effects on HEG [7, 17], and thus are the preferred parameters in HEG prediction models.

Trends, evident in historical data, show that the need for energy increases naturally as population increases. Population, energy consumption, and HEG data generally change in parallel with one another. GDP, a critical factor that reflects the economic performance of countries, changes in direct proportion to energy consumption. As the GDP increases, the economic activities in the country, especially the production of industrial products, increase. Consequently, there are related increased needs for energy.

In $2018,31.2 \%$ of Turkey's total electricity energy consumption was provided from renewable energy sources [4], including hydroelectric energy (63\% of that renewable energy). A majority of the energy used in thermal power plants is imported natural gas [3]. As the demand for GEED and primary energy increases, governments are investing more in HEG, which is a clean, domestic source of production, to reduce dependency on foreign energy sources. Investments in HEG aim to increase installed capacity. However, the contribution of HEG to total installed capacity should be considered in the context of other energy investments. As GEED and primary energy consumption increase, investments in energy production, including HEG, should increase, thereby increasing the installed capacity of HEG.

The climate factor of temperature is an important factor affecting HEG. Because changes in temperature relate directly to all other climate factors, they alter climate factor dynamics. For example, increasing temperatures affect evaporation, precipitation, surface runoff, aqueous saturation of the soil, and water flow volume in rivers. Therefore, temperature is closely related to HEG.

\subsection{Data Used}

To estimate Turkey's HEG, the factors of GDP, population, AYT, installed capacity GEED, and energy consumption data were used as independent variables. The input datasets cover the period of 1980-2018. The data are divided into a training set, used to develop the model, and a test set, used to determine the accuracy of the developed model. The training set consists of data from the years 1980-2010 and the test set consists of data from the years of 2011-2018. Data collected from different sources for each independent variable are presented in Figure 4.

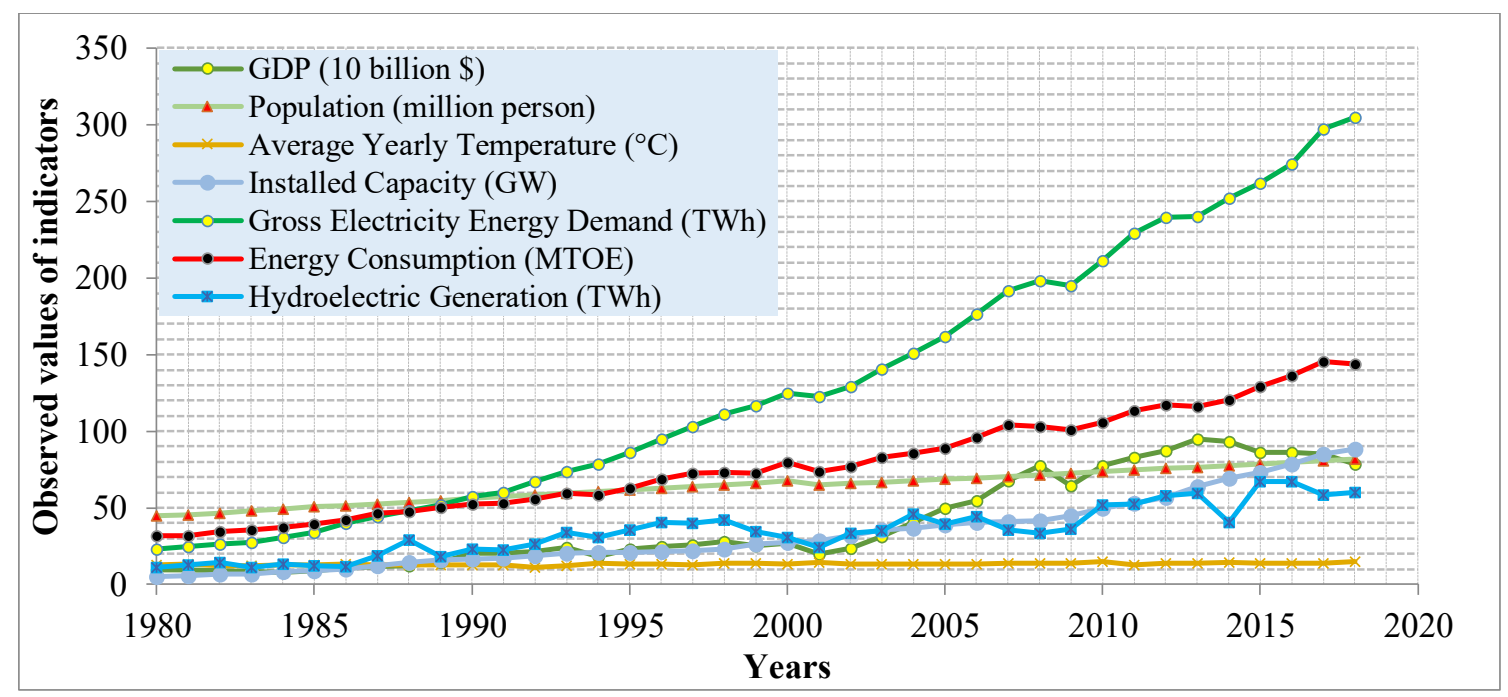

Figure 4. Variations in hydroelectric generation and predictor variables [33-37]. 
GDP, population, and AYT data were obtained from the Turkish Head of Strategy and Budget [33], Turkish Statistical Institute [34], and Turkish State Meteorological Service [35], respectively. Installed power, GEED, and HEG data were obtained from TEIAS [36]. Energy consumption data were obtained from the Ministry of Energy and Natural Resources [37]. To shorten the optimization process and facilitate the development of the most suitable ANN model, all data were normalized to the interval [0.1, $0.9]$ with eq. (8). Generally, the results of activation functions are in the [0,1] interval [27]. To produce more effective results from the activation functions, which were used in ANN input and output layers, the range of $[0.1,0.9]$ was employed here.

Normalized value $=\left[\frac{\text { raw value }- \text { minimum value }}{\text { maximum value }- \text { minimum value }}\right] \times(0.9-0.1)+0.1$

\section{DEVELOPMENT AND PERFORMANCE EVALUATION OF THE FORECASTING MODEL}

The three-layer network used in this study, includes an input layer, hidden layer, and output layer, which is presented in Figure 5. GDP, population, AYT, installed capacity, GEED, and energy consumption values are used in the input layer. HEG, which is the predicted variable, is in the output layer. BP, ABC, and Jaya algorithms were used to train the network. The smallest convergence values obtained for the trained ANN models are presented in Table 1. Error values are calculated using real values.

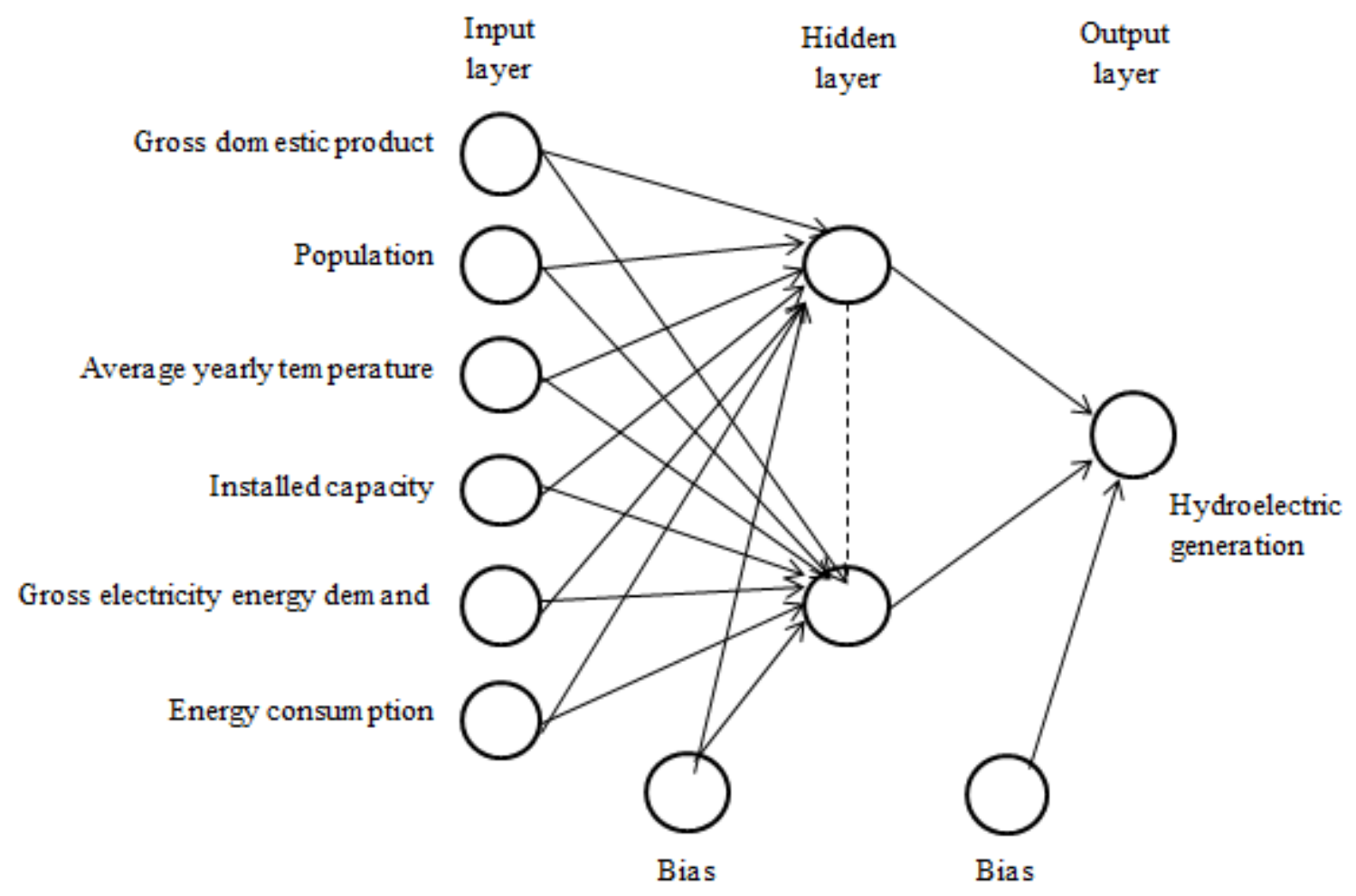

Figure 5. Proposed ANN model for HEG prediction 
Table 1. The model results for training set

\begin{tabular}{|c|c|c|c|}
\hline \multirow{2}{*}{$\begin{array}{c}\text { ANN } \\
\text { architecture }\end{array}$} & \multicolumn{3}{|c|}{$\operatorname{MSE}\left((\mathrm{TWh})^{2}\right)$} \\
\hline & ABC Algorithm & TLBO Algorithm & Jaya Algorithm \\
\hline $4-5-1$ & 21.402 & 17.982 & 14.508 \\
\hline $4-10-1$ & 26.982 & 21.204 & 22.518 \\
\hline $4-15-1$ & 33.552 & 23.832 & 23.130 \\
\hline $4-20-1$ & 40.896 & 33.174 & 24.786 \\
\hline
\end{tabular}

Note: The bold value is error value for the proposed model.

The best convergence values in all ANN models are obtained when there are 5 neurons in the hidden layer (see Table 1). As the number of neurons in the hidden layer increases, the error values found for the training set increase. In addition, as the number of neurons used increases, the optimization process gets longer. The smallest convergence value is found in the $150^{\text {th }}$ iteration for ANN-Jaya (4-5-1) and in the $562^{\text {nd }}$ iteration for ANN-Jaya (4-20-1). This situation reflects a pattern wherein a greater number of neurons in the hidden layer yields a greater number of ANN weights to be optimized. The best convergence (minimum MSE) values found for ANN-BP, ANN-ABC, and ANN-Jaya are 14.508, 17.982, and 21.402 , respectively. As can be seen from these values, the Jaya algorithm performed $32.2 \%$ and $19.3 \%$ better than the $\mathrm{BP}$ and $\mathrm{ABC}$ algorithms, respectively, in ANN training.

These MSE values (presented in Table 1) are the error values calculated for the training set of the developed ANN models. Alone, they do not indicate the predictive power of the network. Due to algorithm limitations (e.g., getting stuck in a local solution and memorizing), predictive power can be low despite high-level training performance. For this reason, the ANN model with the smallest training error does not always have the highest predictive power. To determine which model has the highest predictive power, the test set error values of the ANN models (Table 2) should be taken into account. According to the values in Table 2, the model having the lowest mean RE, RMSE, and MAE values is the ANN-Jaya (4-5-1) model with 5 neurons in the hidden layer. The average RE, RMSE, and MAE error values obtained for the ANN-Jaya (4-5-1) model with the test set data are 3.224\%, 9.672, and 7.092, respectively. Considering the error values calculated for both the training and test sets, the best model is the ANN-Jaya (4-5-1) model with 5 neurons in the hidden layer. $\mathrm{R}$ and $\mathrm{U}$-statistic values calculated to describe the accuracy of the proposed model (training R, 0.893; test R, 0.935; training U-statistic, 0.018; and test $\mathrm{R}, 0.007$ ) show that the predictive power of the proposed model is acceptable.

Table 2. The model results for testing set

\begin{tabular}{|c|c|c|c|c|c|c|c|c|c|}
\hline \multirow[t]{2}{*}{$\begin{array}{c}\text { ANN } \\
\text { architecture }\end{array}$} & \multicolumn{3}{|c|}{$\begin{array}{c}\text { Average relative } \\
\text { error }(\%)\end{array}$} & \multicolumn{3}{|c|}{ RMSE (TWh) } & \multicolumn{3}{|c|}{ MAE (TWh) } \\
\hline & $\mathrm{ABC}$ & TLBO & Jaya & $\mathrm{ABC}$ & TLBO & Jaya & $\mathrm{ABC}$ & TLBO & Jaya \\
\hline $4-5-1$ & 4.688 & 3.996 & 3.224 & 13.264 & 11.988 & 9.672 & 10.120 & 8.791 & 7.092 \\
\hline $4-10-1$ & 5.140 & 4.756 & 4.712 & 15.420 & 14.268 & 14.136 & 11.308 & 10.463 & 10.366 \\
\hline $4-15-1$ & 5.996 & 5.508 & 5.004 & 17.988 & 16.524 & 15.012 & 13.191 & 12.117 & 11.008 \\
\hline $4-20-1$ & 7.456 & 7.372 & 5.296 & 22.368 & 22.116 & 15.888 & 16.403 & 16.218 & 11.651 \\
\hline
\end{tabular}

Note: Theboldvaluesareerrorvaluesforthebest model.

Previously reported average RE values of models developed to predict Turkey's HEG are $4.60 \%$, reported by Uzlu et al. [7], and 5.76\%, reported by Cinar et al. [17]. These values are greater than the average RE values calculated for the test set with the presently proposed ANN-Jaya model, affirming that the predictive power of the proposed ANN-Jaya model can be considered acceptable. 


\section{HEG FORECASTS}

Turkey's HEG values were estimated for the years 2019-2030 in two scenarios using the proposed model. The population data used in the scenarios were taken from the Turkish Statistical Institute population projection [34]. Installed capacity and GEED values were obtained from TEIAS' 10 -year demand forecast report [38]. Energy consumption data were obtained from Tefek et al.'s study [39]. The empirical GDP growth rate of $6.82 \%$ was employed. AYT values were obtained by regression analysis. The same population, GDP, AYT, and installed capacity values were used in both scenarios; GEED and energy consumption values differed between the scenario 1 (low energy demand) and 2 (high energy demand). The data used in the scenario 1 and 2 are presented in Tables 3 and 4, respectively.

Table 3. The data regarding GDP, population, AYT, installed capacity, GEED and energy consumption amounts used in scenarios

\begin{tabular}{lllllllll}
\hline Year & $\begin{array}{l}\text { GDP } \\
\text { (Billion\$) }\end{array}$ & $\begin{array}{l}\text { Population } \\
\left(10^{6}\right)\end{array}$ & AYT $\left({ }^{\circ} \mathrm{C}\right)$ & $\begin{array}{l}\text { Installed } \\
\text { capacity } \\
(\mathrm{MW})\end{array}$ & GEED $(\mathrm{TWh})$ & \multicolumn{2}{c}{$\begin{array}{c}\text { Energy } \\
\text { consumption } \\
\text { (MTOE) }\end{array}$} \\
\cline { 2 - 9 } & $\begin{array}{l}\text { Growth } \\
\text { rate }\end{array}$ & $\begin{array}{l}\text { TURKSTAT } \\
{[34]}\end{array}$ & $\begin{array}{l}\text { Regression } \\
\text { analysis }\end{array}$ & $\begin{array}{l}\text { TEIAS } \\
{[38]}\end{array}$ & $\begin{array}{l}\text { TEIAS } \\
\text { [38] Low } \\
\text { demand }\end{array}$ & $\begin{array}{l}\text { TEIAS } \\
\text { [38]High } \\
\text { demand }\end{array}$ & $\begin{array}{l}\text { Low } \\
\text { Demand } \\
{[39]}\end{array}$ & $\begin{array}{l}\text { High } \\
\text { Deman } \\
\text { d [39] }\end{array}$ \\
\hline 2019 & 837.562 & 82.886 & 14.22 & 96536 & 315.807 & 323.788 & 143.9 & 150.3 \\
2020 & 894.683 & 83.9 & 14.27 & 102455 & 328.409 & 343.242 & 148.7 & 156.7 \\
2021 & 955.701 & 84.909 & 14.32 & 108046 & 341.037 & 363.443 & 153.7 & 163.3 \\
2022 & $1,020.880$ & 85.911 & 14.36 & 112368 & 354.156 & 384.848 & 159 & 170.3 \\
2023 & $1,090.504$ & 86.907 & 14.41 & 115739 & 367.876 & 407.889 & 164.7 & 177.6 \\
2024 & $1,164.876$ & 87.886 & 14.46 & 118054 & 381.814 & 431.664 & 170.6 & 185.3 \\
2025 & $1,244.321$ & 88.845 & 14.50 & 119069 & 396.139 & 456.471 & 176.9 & 193.4 \\
2026 & $1,329.183$ & 89.785 & 14.55 & 121450 & 410.53 & 482.263 & 183.6 & 201.9 \\
2027 & $1,419.833$ & 90.704 & 14.60 & 123879 & 424.973 & 508.611 & 190.9 & 210.8 \\
2028 & $1,516.666$ & 91.601 & 14.64 & 126357 & 439.496 & 535.941 & 198.7 & 220.2 \\
2029 & $1,620.103$ & 92.476 & 14.69 & 130148 & 454.136 & 564.135 & 207.1 & 230 \\
2030 & $1,730.594$ & 93.329 & 14.74 & 133702 & 468.399 & 592.844 & 216.2 & 240.3 \\
\hline
\end{tabular}

Table 4. Scenarios for Turkey's hydroelectric energy generation

\begin{tabular}{|c|c|c|c|c|c|c|}
\hline Scenarios & GDP & Population & AYT & Installed capacity & GEED & $\begin{array}{l}\text { Energy } \\
\text { consumption }\end{array}$ \\
\hline Scenario 1 & $\begin{array}{l}\text { The original } \\
\text { growth } \\
\text { rate (about } \\
6.82 \%)\end{array}$ & $\begin{array}{l}\text { The population } \\
\text { data obtained } \\
\text { from } \\
\text { TURKSTAT } \\
\text { [34] }\end{array}$ & $\begin{array}{l}\text { The data } \\
\text { obtained } \\
\text { used } \\
\text { regression } \\
\text { analyses }\end{array}$ & $\begin{array}{l}\text { The data received } \\
\text { from TEIAS } \\
\text { projection [38] }\end{array}$ & $\begin{array}{l}\text { The data } \\
\text { obtained from } \\
\text { TEIAS [38] } \\
\text { with low } \\
\text { demand }\end{array}$ & $\begin{array}{l}\text { The data } \\
\text { obtained from } \\
\text { Tefek et al. } \\
\text { [39] with low } \\
\text { demand }\end{array}$ \\
\hline Scenario 2 & $\begin{array}{l}\text { The original } \\
\text { growth } \\
\text { rate (about } \\
6.82 \% \text { ) }\end{array}$ & $\begin{array}{l}\text { The population } \\
\text { data obtained } \\
\text { from } \\
\text { TURKSTAT } \\
\text { [34] }\end{array}$ & $\begin{array}{l}\text { The data } \\
\text { obtained } \\
\text { used } \\
\text { regression } \\
\text { analyses }\end{array}$ & $\begin{array}{l}\text { The data received } \\
\text { from TEIAS } \\
\text { projection [38] }\end{array}$ & $\begin{array}{l}\text { The data } \\
\text { obtained from } \\
\text { TEIAS [38] } \\
\text { with high } \\
\text { demand }\end{array}$ & $\begin{array}{l}\text { The data } \\
\text { obtained from } \\
\text { Tefek et al. } \\
\text { [39] with high } \\
\text { demand }\end{array}$ \\
\hline
\end{tabular}

The HEG values estimated by ANN-Jaya (4-5-1) are reported in Table 5 and Figure 6 . The ANN-Jaya (45-1) model predicts HEG values for Turkey in 2030 of $104.81 \mathrm{TWh}$ under low energy demands (scenario 1) and of 124.66 TWh under high energy demands (scenario 2). Turkey is thus in a favorable situation to benefit from maximizing HEG, which is an environmentally-sensitive renewable and indigenous energy 
source. Importantly, HEG projections for Turkey have been published for 2012-2021 [7] and 2017-2021 [40], but, before now, none have been published for years beyond 2021. The 2021 projections (67.62$78.36 \mathrm{TWh})$ obtained in this study overlap with the TEIAS projections for 2021 (69.39-116.56 TWh) [40] as well as Uzlu et al.'s prior projections (69.13-76.52 TWh) [7], affirming the accuracy of the presently developed projection model.These data indicate that Turkey will continue to benefit from a relatively low HEG level in 2021 and beyond. However, to become independent of foreign energy, Turkey should pursue a policy to augment HEG development.

\begin{tabular}{lll}
\multicolumn{3}{l}{ Table 5. Future projections of } \\
\multicolumn{3}{l}{ hydroelectric energy inTWh } \\
according to current study \\
\hline Year & Scenario 1 & Scenario 2 \\
\hline 2019 & 63.15 & 71.57 \\
2020 & 65.29 & 74.83 \\
2021 & 67.62 & 78.36 \\
2022 & 70.23 & 82.22 \\
2023 & 73.27 & 86.48 \\
2024 & 76.94 & 91.26 \\
2025 & 81.51 & 96.67 \\
2026 & 87.37 & 102.91 \\
2027 & 93.07 & 110.21 \\
2028 & 98.45 & 116.73 \\
2029 & 102.25 & 121.47 \\
2030 & 104.81 & 124.66 \\
\hline
\end{tabular}

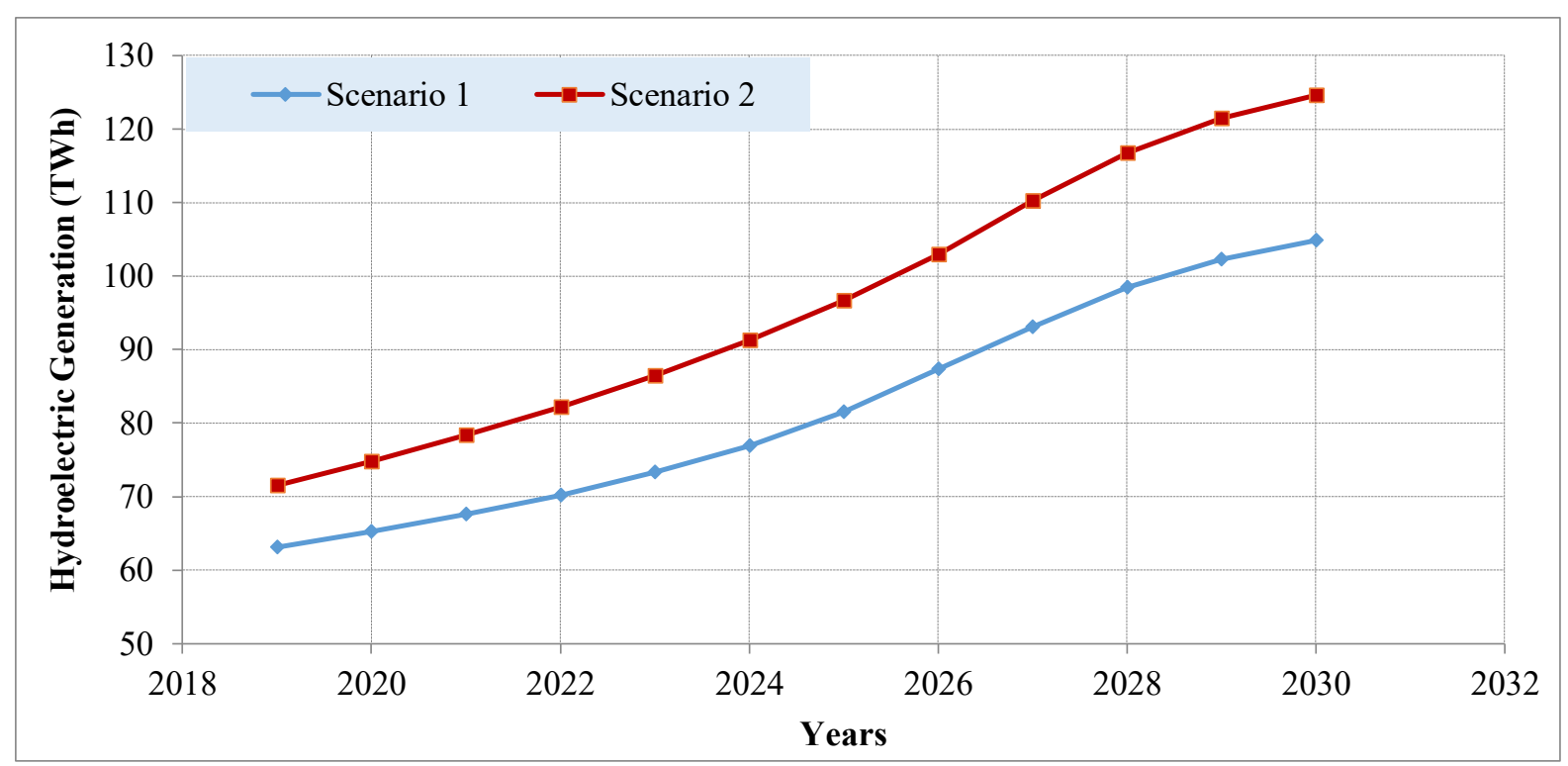

Figure 6. Comparison of the two scenarios for Turkey's hydroelectric energy generation

To meet GEED projections predicted by the present data and TEIAS' electrical energy demand projections [40], the portion of energy produced by HEG should be increased in Turkey (Table 6). The Turkish government aims to produce $30 \%$ of its electrical energy from HEG by 2023 . The present data indicate that Turkey is currently on pace for a HEG energy contribution in the range of $18-23.5 \%$ in 2023. For 2021, the present data predict a HEG contribution in the range of $18.6-23.0 \%$, which is slightly 
lower than but close to the previously predicted range for 2021 of $14.8-18 \%$ [7]. These results clearly show that the Turkish government should revise its energy investments and invest more in HEG to reach its desired HEG targets.

Table 6.Hydropower's supply rate of Turkey's total annual electricity demand, between 2019 and 2030

\begin{tabular}{|c|c|c|c|c|}
\hline \multirow[t]{4}{*}{ Year } & \multicolumn{4}{|c|}{$\%$ of the Total annual electricity demand } \\
\hline & \multicolumn{4}{|c|}{ Current study } \\
\hline & \multicolumn{2}{|l|}{ Scenario 1} & \multicolumn{2}{|l|}{ Scenario 2} \\
\hline & $\begin{array}{l}\text { In the case } \\
\text { of low } \\
\text { demand } \\
{[40]}\end{array}$ & $\begin{array}{l}\text { In the case } \\
\text { of high } \\
\text { demand } \\
{[40]}\end{array}$ & $\begin{array}{l}\text { In the case } \\
\text { of low } \\
\text { demand } \\
{[40]}\end{array}$ & $\begin{array}{l}\text { In the case } \\
\text { of high } \\
\text { demand } \\
{[40]}\end{array}$ \\
\hline 2019 & 20.0 & 19.5 & 22.7 & 22.1 \\
\hline 2020 & 19.9 & 19.0 & 22.8 & 21.8 \\
\hline 2021 & 19.8 & 18.6 & 23.0 & 21.6 \\
\hline 2022 & 19.8 & 18.2 & 23.2 & 21.4 \\
\hline 2023 & 19.9 & 18.0 & 23.5 & 21.2 \\
\hline 2024 & 20.2 & 17.8 & 23.9 & 21.1 \\
\hline 2025 & 20.6 & 17.9 & 24.4 & 21.2 \\
\hline 2026 & 21.3 & 18.1 & 25.1 & 21.3 \\
\hline 2027 & 21.9 & 18.3 & 25.9 & 21.7 \\
\hline 2028 & 22.4 & 18.4 & 26.6 & 21.8 \\
\hline 2029 & 22.5 & 18.1 & 26.7 & 21.5 \\
\hline 2030 & 22.4 & 17.7 & 26.6 & 21.0 \\
\hline
\end{tabular}

\section{CONCLUSIONS}

Estimates of HEG values under different scenarios are critical for the development of energy policies. In this study, Turkey's HEG values were modeled from 1980 through 2030 using the ANN-Jaya technique based on GDP, population, AYT, installed capacity, and GEED input data. The accuracy of the proposed ANN-Jaya model is supported by comparisons with the ANN-BP and ANN-ABC models. Comparing the three models, the smallest error values for both the test and training datasets were obtained with ANNJaya (4-5-1). Considering the average RE values calculated for the test set, ANN-Jaya performs 19.3\% better than ANN-ABC and $31.2 \%$ better than ANN-BP. The average RE, RMSE, and MAE values calculated for ANN-Jaya (4-5-1) (3.224\%, 9.672, and 7.092, respectively) indicate that the method can be used to estimate Turkey's HEG values in the period of 2019-2030.

The present data obtained for low- and high-energy demand scenarios indicate that HEG values for Turkey in 2030 will be between 104.8 and 124.6 TWh. According to these scenarios and TEIAS'GEED projections [40], the ratio of HEG needed to meet GEED will vary between $17.7 \%$ and $16.0 \%$. The obtained results show that Turkey will not be able to reach its targets related to hydroelectric energy in 2030. The decrease in the share of hydroelectric energy production in the total energy production will cause an increase in the amount of imported energy and greenhouse gas emissions. This situation will adversely affect both the national economy and environmental health. If the plans for renewable energy production of Turkey are not revised, the country will face serious economic, environmental and energy problems. These results show that Turkey is lagging its energy composition targets and should revise its energy policies. 
For Turkey to reduce its dependence on foreign energy, it will need to increase its HEG capacity. Because Turkey is a developing country, the Turkish government should plan HEG development carefully to maximize the efficiency of its use of resources. Therefore, there is a need for realistic projections related to Turkey's renewable energy production to minimize the possibility of encountering problems mentioned above. The presently reported HEG projections can assist policy makers in their energy investment decision-making. In addition, given that the present results were quite satisfactory, researchers should be encouraged to use the Jaya algorithm for energy modeling.

\section{REFERENCES}

[1] Natural Gas Distrubition Companies Association of Turkey (GAZBIR). Energy situation in Turkey and in the world.https://www.gazbir.org.tr/uploads/page/Dunya-ve-Turkiye-EnerjiGorunumu.pdf, Accessed:10/09/2020.

[2] Istemi, B., \& Ediger, V .Ş. (2016). Forecasting the coal production: Hubbert curve application on Turkey's lignite fields. Resources Policy, 50, 193-203. https://doi.org/10.1016/j.resourpol.2016.10.002

[3] Republic of Turkey Ministry of Energy and Natural Resources(MENR) https://enerji.gov.tr/bilgimerkezi-enerji-hidrolik-en, Accessed:10/09/2020.

[4] Turkish Electricity Transmission Corporation (TEİAŞ). https://www.teias.gov.tr/enUSAccessed:10/09/2020.

[5] Uzlu, E., Akpınar, A., \& Kömürcü, M.İ. (2011). Restructuring of Turkey’s electricity market and the share of hydropower energy: The case of the Eastern Black Sea Basin. Renewable Energy, 36, 676-688.https://doi.org/10.1016/j.renene.2010.08.012

[6] General Directorate of State Water Works (DSI). 2020 Annual Report. https://cdniys.tarimorman.gov.tr/api/File/GetFile/425/KonuIcerik/759/1107/DosyaGaleri/DS\%C4 \%B0\%202020-yili-faaliyet-raporu.pdf, Accessed:10/09/2020.

[7] Uzlu, E., Akpınar, A., Öztürk, H.T., Nacar, S., \& Kankal, M. (2014). Estimates of hydroelectric generation using neural networks with artificial bee colony algorithm for Turkey. Energy, 69, 638-647. https://doi.org/10.1016/j.energy.2014.03.059

[8] Geem, W.Z., \& Roper, W. E. (2009). Energy demand estimation of South Korea using artificial neural network. Energy Policy, 37, 4049-4054.https://doi.org/10.1016/j.enpol.2009.04.049

[9] Ekonomou, L. (2010). Greek long-term energy consumption prediction using artificial neural networks. Energy, 35, 512-517. https://doi.org/10.1016/j.energy.2009.10.018

[10] Kankal, M., Akpinar, A., Komurcu, M. I., \&Ozsahin, T. S. (2011). Modeling and forecasting of Turkey's energy consumption using socio-economic and demographic variables. Applied Energy, 88, 1927-1939. https://doi.org/10.1016/j.apenergy.2010.12.005

[11] Pao, H. T. (2006). Comparing linear and nonlinear forecasts for Taiwan's electricity consumption. Energy, 31, 2129-2141. https://doi.org/10.1016/j.energy.2005.08.010

[12] Kandananond, K. (2011). Forecasting electricity demand in Thailand with an artificial neural network approach. Energies, 4, 1246-1257. https://doi.org/10.3390/en4081246

[13] Uzlu, E. (2019). Application of Jaya algorithm-trained artificial neural networks for prediction of energy use in the nation of Turkey. Energy Sources, Part B: Economics, Planning, And Policy, 14, 183-200. https://doi.org/10.1080/15567249.2019.1653405

[14] Uzlu, E., \& Dede, T. (2020). Estimating electric energy consumption in turkey using artificial neural networks optimized with jaya algorithm. Gazi Üniversitesi fen BilimleriDergisi Part C: TasarımveTeknoloji, 8, 511-528. https://doi.org/10.29109/gujsc.684334 
[15] Wang, Z. X., Li, Q., \&Pei, L. L. (2017). Grey forecasting method of quarterly hydropower production in China based on a data grouping approach. Applied Mathematical Modeling, 51, 302-316. https://doi.org/10.1016/j.apm.2017.07.003

[16] Coulibaly, P., \& Anctil, F. (2000). Neural network-based long-term hydropower forecasting system. Computer-Aided Civil and Infrastructure Engineering, 15, 355-364. https://doi.org/10.1111/0885-9507.00199

[17] Cinar, D., Kayakutlu, G., \& Daim, T. (2010). Development of future energy scenarios with intelligent algorithms: case of hydro in turkey. Energy, 35, 1724-1729.

https://doi.org/10.1016/j.energy.2009.12.025

[18] Yuksel, I. (2008). Hydropower in Turkey for a clean and sustainable energy future. Renewable and Sustainable Energy Reviews, 12, 1622-1640. https://doi.org/10.1016/j.rser.2007.01.024

[19] Toklu, E. (2013). Overview of potential and utilization of renewable energy sources in Turkey. Renewable Energy, 50, 456-463. https://doi.org/10.1016/j.renene.2012.06.035

[20] Kentel, E., \& Alp, E. (2013). Hydropower in Turkey: Economical, social and environmental aspects and legal challenges. Environmental Sciences and Policy, 31, 34-43. https://doi.org/10.1016/j.envsci.2013.02.008

[21] Yuksel, I. (2010). Hydropower for sustainable water and energy development. Renewable and Sustainable Energy Reviews, 14 , 462-469. https://doi.org/10.1016/j.rser.2009.07.025

[22] Capik, M., Yilmaz, A. O., \& Cavusoglu, I. (2012). Hydropower for sustainable energy development in Turkey: the small hydropower case of the eastern black sea region. Renewable and Sustainable Energy Reviews, 16, 6160-6172.https://doi.org/10.1016/j.rser.2012.06.005

[23] Rao, R. V. (2016). Jaya: A simple and new optimization algorithm for solving constrained and unconstrained optimization problems. International Journal of Industrial Engineering Computations, 7, 19-34.https://doi.org/10.5267/j.ijiec.2015.8.004

[24] Rao, R. V., More, K. C., Taler, J., \&Oclon, P. (2016). Dimensional optimization of a microchannel heat sink using Jaya algorithm. Applied Thermal Engineering, 103, 572-582.

https://doi.org/10.1016/j.applthermaleng.2016.04.135

[25] Du, D. C., Vinh, H. H., Trung, V. D., Quyen, N. T. H., \&Trung, N. T. (2018). Efficiency of Jaya algorithm for solving the optimization-based structural damage identification problem based on a hybrid objective function. Engineering Optimization, 50, 1233-1251.

https://doi.org/10.1080/0305215X.2017.1367392

[26] Kankal, M., \&Uzlu, E. (2017). Neural network approach with teaching-learning-based optimization for modeling and forecasting long-term electric energy demand in Turkey. Neural Computing and Applications, 28, 737-747. https://doi.org/10.1007/s00521-016-2409-2

[27] Uzlu, E., Kankal, M., Akpınar, A, \& Dede, T. (2014). Estimates of energy consumption in Turkey using neural networks with the teaching-learning-based optimization algorithm. Energy, 75, 295303. https://doi.org/10.1016/j.energy.2014.07.078

[28] Çunkaş, M., \&Altun, A. A. (2010). Long term electricity demand forecasting in Turkey using artificial neural networks. Energy Sources, Part B: Economics, Planning and Policy, 5, 279-289. https://doi.org/10.1080/15567240802533542

[29] Rumelhart, D. E., Hinton, G. E., \& Williams, R. J. (1986). Learning representations by backpropagating errors. Nature, 323, 533-536.https://doi.org/10.1038/323533a0

[30] Uzlu, E. Estimates of greenhouse gas emission in Turkey with grey wolf optimizer algorithmoptimized artificial neural networks. Neural Computing and Applications, [article in press]. https://doi.org/10.1007/s00521-021-05980-1 
[31] Rao, R.V., \&Saroj, A. (2017). Constrained economic optimization of shell-and-tube heat exchangers using elitist-Jaya algorithm. Energy, 128, 785-800.

https://doi.org10.1016/j.energy.2017.04.059

[32] Rao, R.V., \&Waghmare, G. (2017). A new optimization algorithm for solving complex constrained design optimization problems. Engineering Optimization, 49, 60-83.

https://doi.org/10.1080/0305215X.2016.1164855

[33] Republic of Turkey Presidency of strategy and Budget (SBB).

http://www.sbb.gov.tr/ekonomik-ve-sosyal-gostergeler/\#1540021349004-1497d2c6-7edf

Accessed:10/09/2020.

[34] Turkish Statistical Institute (TURKSTAT). Main statistics, Population and Demography, Population Statistics, Population by Years, Age Group and Sex, Census of Population - ABPRS. http://www.turkstat.gov.tr/UstMenu.do?metod=temelist, Accessed:10/09/2020.

[35] Turkish State Meteorological Service. Statistical Analysis of Turkey's Meteorological Parameters. https://www.mgm.gov.tr/FILES/resmi-istatistikler/yayinlar/parametre-analiz.pdf Accessed:10/09/2020.

[36] Turkish Electricity Transmission Corporation (TEIAS). Turkey's gross electric generation by the electricity utilities and exports-imports-gross demand. https://www.teias.gov.tr/tr-TR/turkiyeelektrik-uretim-iletim-istatistikleri, Accessed:10/09/2020.

[37] Republic of Turkey Ministry of Energy and Natural Resources(MENR): General Directorate of Electricity Affairs. Statistics, balance sheets. https://www.eigm.gov.tr/tr-TR/DengeTablolari/Denge-Tablolari?page=2, Accessed:10/09/2020.

[38] Turkish Electricity Transmission Corporation (TEIAS). 10-year demand forecasts report. https://www.teias.gov.tr, Accessed:10/09/2020.

[39] Tefek, M. F., Uğuz, H., \&Güçyetmez, M. (2019). A new hybrid gravitational search-teachinglearning-based optimization method for energy demand estimation of Turkey. Neural Computing and Applications, 31, 2939-2954. https://doi.org/10.1007/s00521-017-3244-9

Accessed:10/09/2020.

[40] Republic of Turkey Energy Market Regulatory Authority (EPDK). Production capacity projection (2017-2021).http://www.epdk.org.tr/Detay/Icerik/3-0-66/elektrikuretim-kapasiteprojeksiyonlari\#, Accessed:10/09/2020. 